\title{
Research on the Flow of Teachers in Public Interest Kindergartens A Case of Chongqing China
}

${ }^{1}$ Chongqing University of Education

Liu Jianhong $^{1 *}$, Lei Ziteng ${ }^{2}$ Chongqing, China

*E-mail:nvnvr@163.com

${ }^{2}$ Huayi Xincun Kindergarten in Yuzhong District, Chongqing, China

Chongqing, China

E-mail:nvnvr@163.com

\begin{abstract}
:
Based on the current situation and problems of the teachers' flow in public interest kindergartens, it is found that the current flow of teachers is a relatively common phenomenon for kindergartens through a survey and interviews with kindergarten teachers and kindergarten principals. In this regard, we have summed up and sorted out the current status and existing problems of the flow of teachers in kindergartens; the current main reasons for the flow of kindergarten teachers are social benefits and work pressure, so we should constantly improve relevant policies and systems and increase investment in teachers, improve the kindergarten management system and build a better development platform for teachers. Teachers, kindergartens, governments and society should actively cooperate to jointly build a good environment for the flow of teachers and promote the development of education.
\end{abstract}

Keywords: public interest kindergartens; teachers; flow;

\section{INTRODUCTION}

With the rapid economic development, china's education has also welcomed the peak of development, and the pace of education reform has accelerated, so does the degree of reform. The development of education is inseparable from the growth of teachers. Excellent teachers are a firm force to promote the development of education and an important resource for the vigorous development of education in china. Due to the scarcity of teachers, and as teachers who are professionals in education and teaching also flow to the rich labor market like talents in other industries, the phenomenon of teacher flow is becoming increasingly common.

In this research, a questionnaire survey method was used to investigate the kindergarten principals and kindergarten teachers on the flow of teachers. The research group was selected from chongqing's public interest kindergarten principals and kindergarten teachers, 136 people in total. A total of 150 questionnaires were distributed, of which 136 were valid and the recovery rate was 90.6\%. This questionnaire is adapted from the questionnaire of flow of teachers in chongqing's public interest kindergartens, which is aimed at kindergarten teachers and kindergarten principals in the whole kindergarten. The questionnaire includes closed single-choice and multiple-choice questions as well as an open-ended question, 60 questions in total.

This paper mainly focuses on the phenomenon of flow of teachers in public interest kindergartens in chongqing. Taking yuzhong district as an example, the teachers in the questionnaire mainly include in-service teachers of public interest kindergartens in yuzhong district, and teachers in private kindergartens that provide public interest services in yuzhong district. The kindergarten principals include the principals of public interest kindergartens in various districts and counties in chongqing and the principals of private kindergartens that provide public interest services.

\section{ANALYSIS OF THE CURRENT SITUATION AND PROBLEMS OF THE FLOW OF TEACHERS IN PUBLIC INTEREST KINDERGARTENS IN CHONGQING}

Regarding the basic situation of teachers in public interest kindergartens in Chongqing, we used the questionnaire survey method to investigate a total of 41 principals and 95 
teachers in public interest kindergartens in Chongqing. Among the teachers surveyed, 92 were in-service kindergarten teachers, and 3 were kindergarten teachers who have left, and the information of the remaining teachers was obtained from the principals.

\subsection{The flow of teachers in public interest kindergartens in Chongqing is unidirectional and has the characteristics of flowing out of the teaching profession.}

At present, the flow of teachers has become a major obstacle to the development of education, and it is also an undeniable social reality, especially in Chongqing's public interest kindergartens.

\subsubsection{The flow of teachers within the teaching profession is unidirectional and out of order}

Most of the flow within the teaching profession is unidirectional upper flow, that is, the flow of teachers in the education system to a better education unit without departing from the identity of the teacher. Although teachers are not lost from the education system as a whole, it will result in uneven distribution of educational resources. For example, teachers in rural kindergartens become weaker. The poor treatment, poor teaching environment, and less income than those in the urban kindergartens are the three important reasons why they are unwilling to go to the rural kindergartens; on the contrary, urban kindergartens with good treatment, advanced teaching equipment, and higher income than rural kindergartens have become "favorite" choices of excellent teachers; public kindergartens provide more stable and relatively easy tasks than private ones.

\subsubsection{The flow of teachers out of the education industry is the true loss of teachers}

The flow of teachers out of the teaching profession mainly refers to the fact that teachers give up the teaching profession and withdraw from the education system, and choose other industries outside the education system as their occupations. This is the true teacher loss. The flow of teachers out of the industry can be divided into three aspects: I. Leaving the post of a teacher for self-employment; II. Choosing to take exams for other undertakings, government agencies or enterprises; III. Choosing to continue to study and enrich their cultural deposits. The most affected areas of the flow of teachers out of the teaching profession are the kindergartens in rural areas and poor areas in the west. The leaving of a large number of outstanding teachers from the post of teachers greatly restricts the development of local education and is not conducive to the improvement of the local economic level.

\subsection{Analysis of problems in the flow of teachers}

\subsubsection{The flow of teachers has the problem of unreasonable flow direction}

The flow of teachers from rural kindergartens to urban kindergartens causes the uneven distribution of urban and rural teachers. In this survey, 25 teachers were transferred from rural to urban areas for teaching, and only 3 were transferred from urban to rural areas; the flow of teachers from private kindergartens to public kindergartens causes too concentrated distribution of talents, which hinders the comprehensive development. The survey revealed that 35 teachers were transferred from private kindergartens to public kindergartens, and only 12 were transferred from public kindergartens to private kindergartens; the ratio of male kindergarten teachers to female kindergarten teachers was uneven, and the loss of male kindergarten teachers was serious.

\subsubsection{There is a problem of concentration of flow destinations for flowing teachers}

During the survey, we found that the vast majority of teachers regarded the teaching profession as a means of survival, and the salary before their flow does not meet their needs in life. That is, their flow is to improve salary and improve the quality of life. Meanwhile, they have high working pressure, and unbalanced pay and gain. 41 teachers believe that there is insufficient space for promotion in the original kindergarten, and there are loopholes in the management system, that is, their flow is to get a better development space and go to a better development platform. As a male teacher, this problem appears more serious. 
Table 1 Reasons affecting the flow of kindergarten teachers

\begin{tabular}{|c|c|c|c|c|c|}
\hline $\begin{array}{c}\text { Reasons for the flow of } \\
\text { kindergarten teachers }\end{array}$ & $\begin{array}{c}\text { High } \\
\text { working } \\
\text { pressure }\end{array}$ & $\begin{array}{c}\text { Low } \\
\text { salary }\end{array}$ & $\begin{array}{c}\text { Low } \\
\text { social } \\
\text { status }\end{array}$ & $\begin{array}{c}\text { Kindergarten } \\
\text { environment } \\
\text { and conditions }\end{array}$ & $\begin{array}{c}\text { Colleague } \\
\text { relationship }\end{array}$ \\
\hline Proportion & $65.9 \%$ & $52.69 \%$ & $41.94 \%$ & $30.11 \%$ & $7.5 \%$ \\
\hline
\end{tabular}

\section{ANALYSIS OF THE REASONS FOR THE FLOW OF TEACHERS IN PUBLIC INTEREST KINDERGARTENS IN CHONGQING}

Through a questionnaire survey on public interest kindergartens in Chongqing, we found the following reasons for the problems in the flow of teachers in public interest kindergartens in Chongqing:

\subsection{Analysis of reasons for flow within the profession}

\subsubsection{Rural preschool education lags behind urban preschool education}

As far as the current national conditions are concerned, the rural economic development is relatively slow, the urban and rural development is uneven, the rural kindergarten running environment cannot be effectively improved, and the teaching facilities and equipment are outdated, resulting in low quality of teaching. At the same time, the safety of preschool children is not effectively guaranteed, and the pressure and responsibility of teachers will increase; most rural parents do not pay attention to their children's preschool education, resulting in a lack of enthusiasm for kindergarten teachers and a lack of professional achievement; in rural public kindergartens, some of the teachers with establishment were assigned to rural kindergartens. Before entering the establishment, their original goal was to teach in urban kindergartens. Many excellent teachers would prefer to teach in economically developed areas for economic reasons.

\subsubsection{The compensation and welfare of public kindergartens have a much larger room for improvement than those of private kindergartens}

The survey revealed that $42.7 \%$ of people think that the compensation and welfare of private kindergartens cannot meet the needs of life and the occupational stability is not as good as that of public kindergartens. Moreover, the wage level is generally low and the proportion of social insurance contributions is not high. In a survey of public interest kindergartens in Chongqing, it was found that among the 95 people surveyed, 31 indicated that their schools did not purchase insurance for them; 41 indicated that their schools had purchased insurance for them; 23 indicated that they did not know whether their schools purchased insurance for them.

Table 2 Situation of kindergarten welfare

\begin{tabular}{|c|l|c|c|c|c|}
\hline $\begin{array}{c}\text { The impact of } \\
\text { kindergarten welfare } \\
\text { on teacher flow }\end{array}$ & Salary & $\begin{array}{c}\text { Job title } \\
\text { assessment }\end{array}$ & $\begin{array}{c}\text { Social } \\
\text { status }\end{array}$ & $\begin{array}{c}\text { Refresher } \\
\text { training }\end{array}$ & $\begin{array}{c}\text { Employment } \\
\text { system }\end{array}$ \\
\hline Proportion & $42.71 \%$ & $19.79 \%$ & $14.58 \%$ & $17.71 \%$ & $5.21 \%$ \\
\hline
\end{tabular}

\subsubsection{Teachers' salary is not proportional to labor intensity}

The labor intensity of private kindergarten teachers is higher than that of public kindergartens, which makes many kindergarten teachers feel that the labor intensity is disproportionate to their income; on the other hand, if teachers have requirements for their own development, but private kindergartens cannot offer training opportunities or good development platforms like public kindergartens so that the future development of teachers is limited, they will think their promotion is hindered. 


\subsection{Analysis of reasons for flow out of the profession}

\author{
3.2.1. Career development is the main reason for \\ the loss of teachers
}

At present, although the salary level of kindergarten teachers has increased, the disposable income is still insufficient. According to our survey, the average salary of most kindergarten teachers is around RMB 3,000, while the salary of new teachers is even lower. In the questionnaire, we found that $47.9 \%$ of teachers whose income is below RMB 3,500 have considered changing positions, indicating that economic reasons are also one of the factors that cause the flow of kindergarten teachers.

Table 3 Impact of income on teacher flow

\begin{tabular}{|c|c|c|}
\hline $\begin{array}{c}\text { The impact of income on } \\
\text { teacher flow }\end{array}$ & Income below RMB 3,500 & Income over RMB 3,500 \\
\hline Want to change positions & $47.9 \%$ & $18.1 \%$ \\
\hline $\begin{array}{c}\text { Do not want to change } \\
\text { positions }\end{array}$ & $34.2 \%$ & $45.5 \%$ \\
\hline Have never thought & $17.9 \%$ & $36.4 \%$ \\
\hline
\end{tabular}

\subsubsection{The social pressure of the teacher profession is the main reason for the loss of teachers}

Due to the age characteristics of preschool children, they do not yet have a good self-care ability and self-protection awareness, which determines the nature of teachers' work that teachers must protect and teach the preschool children. With the high level of attention to children from all walks of life, kindergarten teachers are facing greater pressure. The survey found that when the kindergarten teachers have a strong sense of social pressure, and the kindergartens cannot build a better development platform for the teachers, they are more likely to leave.

\subsubsection{Difficulties in preparing for teacher establishment are the main reason for the loss of teachers}

At present, there is a shortage of teachers with establishment. The survey found that from December 2018 to April 2019, the number of teachers with establishment in Yuzhong District, Chongqing was less than 10. In the establishment assessment of the kindergarten, the admission rate was only $1 \%$. This is more common in the current establishment assessment of Yuzhong District. Teachers who have no establishment are often frustrated during the continuous assessment. Due to a lack of professional recognition, they leave the post.

\subsubsection{Traditional ideas are the main reason for the loss of male kindergarten teachers}

Due to the inherent gender differences and thinking differences between males and females, male teachers in kindergartens need to adjust their status to adapt to the trivial and complicated tasks of kindergartens in child care work. 36 years old is a period of development of children's concrete image thinking. Male teachers tend to analyze and solve problems with abstract logical thinking, which is easy to separate from children's thinking, so it is not easy to let children understand. Moreover, many male teachers in kindergartens are deeply influenced by traditional Chinese ideas believing that teachers in kindergartens are women's occupations. Therefore, male teachers in kindergartens bear more pressure from public opinion, which is also the reason for their departure. 


\section{COUNTERMEASURES FOR THE FLOW OF TEACHERS IN PUBLIC INTEREST KINDERGARTENS IN CHONGQING}

\subsection{Improve the kindergarten management system and enhance teachers' sense of accomplishment and belonging}

In order to solve the problem of the lagged rural education, in the practice of rural preschool education, the government needs to vigorously explain the importance of preschool education and family education to the villagers; then, it needs to improve the rural kindergarten hardware facilities and enhance the environmental safety and education of the kindergartens; after the first two conditions have been improved, teachers' sense of accomplishment and belonging will naturally increase, and there will be a basis for stable flow. In addition, it also needs to improve the Private Education Law, focus on standardizing the management system of kindergarten teachers and staff, clarify the access standards for kindergartens, refine the relevant provisions on teacher recruitment, clarify the status of kindergarten teachers, and safeguard the basic rights of teachers by improving relevant laws.

\subsection{Ease the pressure of teachers' life from various aspects and build a better development platform}

\subsubsection{Improve compensation and welfare to ease teachers' pressure}

The work pressure of kindergarten teachers comes from economic pressure and social pressure, and kindergarten teachers generally think that their social status is not high. First of all, the government should provide a comprehensive definition of the kindergarten teachers from an official point of view; second, the media, as the vane of the society, should promote a positive image for the kindergarten teachers and let the public subconsciously identify the kindergarten teachers; finally, the kindergarten should actively communicate with teachers, do a good job in teacher's ideological guidance, and enhance teachers' professional identity and happiness.

\subsubsection{Provide diverse development space for kindergarten teachers}

Male teachers in kindergartens are an important group of teachers lost. Government departments and kindergartens should pay more attention to the implementation of policies for male teachers, explore the path of professional development of male teachers in kindergartens, provide diverse development space for kindergarten teachers, and train kindergarten male teachers in professional self-identity.

\subsection{Issue relevant policies to ensure the stability of kindergarten teachers}

\subsubsection{Improve the legal system to standardize the teacher management mechanism}

The premise of ensuring the stability of kindergarten teachers is improvement of the legal system. "Double factor drive" tells us that although a sound legal system is not able to stimulate the enthusiasm of employees to a certain extent, if it is missing or there are problems, it will defeat their enthusiasm and they will become negative. Therefore, improvement of the relevant laws for the kindergarten teacher system not only guarantees the kindergarten teachers on the microscopic level, but also promotes the development of kindergarten education and kindergartens themselves on the macroscopic level.

\subsubsection{Innovate support methods to solve the problem of brain drain}

The survey shows that the current support for public interest kindergartens is mainly rent reduction and exemption, arrangement of outstanding public kindergarten teachers to serve in private preschool institutions and other new methods. It is also necessary to think about and to innovate ways to support kindergartens, not only to solve the problem that private kindergartens cannot retain talents, but also to solve the problem of insufficient government funds. There is a large gap between the private and public kindergartens in terms of teacher resources, teacher salaries, and social benefits due to insufficient funds, which has caused many problems, the most important of which is the flow and instability of teachers. Therefore, the emphasis on the development of preschool education should not be a slogan, but should be expressed in action.

\subsubsection{Strengthen the implementation supervision and implement the teacher guarantee system}


Set up a special agency that can effectively manage and handle the administrative affairs of preschool education. The implementation of laws shall be adjusted according to circumstances, and policies and regulations that meet the development requirements of the region shall be formulated combined with the actual situation of the region. At the same time, it is necessary to strictly implement the access system for private education, development and reform, financial management and personnel management, and labor security and health. The government department shall establish an inspection, supervision and evaluation system and increase its enforcement efforts to punish kindergartens that violate teachers' rights, such as withholding salaries, failing to pay social insurance, and arbitrarily increasing the workload of teachers, so that they dare not break the law and cannot break the law.

\subsection{Improve the management level of kindergartens}

\subsubsection{Improve managers' own quality and ability}

First, strengthen service awareness. Preschool education is the foundation of other education. Kindergartens should think about educational issues from the perspective of promoting the vigorous development of preschool education in China. Therefore, guiding the kindergarten management to establish a strong sense of social responsibility and service awareness is very important.

Second, pay attention to the study of advanced management theory and improve the management level of the management. The survey found that the construction and management of the kindergarten teacher teams are beneficial to the development of the kindergartens. Therefore, it is necessary to guide the kindergarten management to strengthen learning awareness and insist on creating a good working atmosphere for the teaching staff.

\subsubsection{Scientifically design salary system and improve performance appraisal mechanism}

Pay attention to compensation, incentives and fairness of salary. Paying attention to the compensation of salaries can mainly help employees solve survival problems, etc., which is the first principle that kindergartens must adhere to when designing a salary system. Resolutely oppose egalitarianism, encourage those who have done well in work, and inspire other teachers to work hard like those teachers. Fairness includes horizontal fairness, that is, equal pay for equal work for employees in the kindergartens, and external fairness, that is, consistent salary design for the same type of employees in the kindergartens.

In the survey, it was found that many kindergartens have a single performance appraisal mechanism. With the progress of the times, the performance appraisal system shall also be improved. The performance appraisal mechanism shall be improved, and the diversification of evaluation subjects, evaluation standards, evaluation contents, and evaluation methods shall be diversified. The evaluation of teachers shall focus on the evaluation of both the process and the results, not only on the qualitative evaluation, but also the quantitative evaluation, In addition, it shall also insist on the unification of the process and the results, and the unification of the qualitative and quantitative evaluations.

\section{CONCLUSION}

The flow of teachers in Public Interest Kindergartens has become a relatively common problem. To improve this problem, we should focus on the development of rural early childhood education, continuously improve the kindergarten management system, relieve the pressure on teachers' lives in many ways, and build a better development platform for teachers, Such as: improving salary and welfare, etc; at the same time, relevant legal systems and policies should be introduced as soon as possible, innovating support methods for Public Interest Kindergartens, strengthening the management and supervision of Public Interest Kindergartens, and continuously improving the management level of kindergartens to ensure universal The teachers of Public Interest Kindergartensare relatively stable.

\section{ACKNOLEDGMENT}

(This paper is the achievement of the Chongqing Higher Education Teaching Reform Research Project in Chongqing, China: Research and Practice of Successive Teaching Pattern Reform Based on the OBE Concept under the Background of Transformation and Development (Project No.: 193265); the achievement of the university-level research platform of Chongqing University of 
Education, "Family Education Research Center for Children Aged 0-6" (Project No.: 16xjpt03)

\section{REFERENCES}

[1] Feng Xiaoxia. Vigorously Developing Public Interest Kindergartens is the Fundamental Solution to the Difficulty and High Cost of Entering the Kindergartens [J], Studies in Preschool Education, May 1, 2010;

[2] Tian Zhilei; Zhang Xue. Problems and Reforms of Financial Investment in Chinese Preschool Education [J]. Journal of Beijing Normal University (Social Science Edition), September 25, 2011

[3] Qin Xufang; Wang Mo. Connotation, Measurement Standards and Policy Recommendations of Public Interest Kindergartens [J], Studies in Preschool Education, July 1, 2012;
[4] Zhuang Xiaoman; Cheng Lisheng. Significance, Dilemma and Countermeasures of Developing Inclusive Private Kindergartens [J], Studies in Preschool Education, November 1, 2012;

[5] Ding Xiutang. Status and Development of Private Preschool Education under the Target Location of "Inclusiveness" [J], Studies in Preschool Education, March 1, 2013;

[6] Fang Jianhua and Deng Heping. Dilemma and Outlet: Research on the Development of Private Kindergartens [J], Journal of the Chinese Society of Education, October 1, 2014;

[7] Liu Ying. Inclusive deviations in the implementation of inclusive preschool education policies: performance, causes and countermeasures $[\mathrm{J}]$, Research in Educational Development, March 25, 2016; 